\title{
Pre-investigation of water electrolysis for flexible energy storage at large scales: The case of the Spanish power system
}

\author{
F. Gutiérrez Martín, A. Ochoa Mendoza, L.M. Rodríguez Antón
}

\begin{abstract}
A B S T R A C T
This report analyzes the basis of hydrogen and power integration strategies, by using water electrolysis processes as a means of flexible energy storage at large scales.

It is a prospective study, where the scope is to describe the characteristics of current power systems (like the generation technologies, load curves and grid constraints), and define future scenarios of hydrogen for balancing the electrical grids, considering the efficiency, economy and easiness of operations.

We focus in the 'Spanish case', which is a good example for planning the transition from a power system holding large reserve capacities, high penetration of renewable energies and limited interconnections, to a more sustainable energy system being capable to optimize the volumes, the regulation modes, the utilization ratios and the impacts of the installations.

Thus, we explore a novel aspect of the 'hydrogen economy' which is based in the potentials of existing power systems and the properties of hydrogen as energy carrier, by considering the electricity generation and demand globally and determining the optimal size and operation of the hydrogen production processes along the country; e.g. the cost production of hydrogen becomes viable for a base-load scenario with $58 \mathrm{TWh} /$ year of power surplus at $0.025 € / \mathrm{kWh}$, and large number electrolyzer plants ( $50 \mathrm{MW}$ ) running in variable mode $\left(1-12 \mathrm{kA} / \mathrm{m}^{2}\right)$.
\end{abstract}

\section{Introduction}

The 'hydrogen economy' can be defined broadly as a long term project capable to combine the cleanliness of hydrogen $\left(\mathrm{H}_{2}\right)$ as an energy carrier with the efficiency of fuel-cells (FCs) to convert the energy in electricity, heat or motion. However, $\mathrm{H}_{2}$ - as electricity - is not an energy resource and must be obtained from other primary sources, where there is a wide agreement to considering water as the most interesting feedstock to produce sustainable hydrogen; the main reason is that renewable energy sources can be integrated in the process $[1,2]$.

Electrolysis represents the most important path to obtain hydrogen from water; it is a mature technology based on the generation of hydrogen and oxygen from water that is 
dissociated by applying direct current electric energy; the hydrogen obtained has a high purity, which is an advantage against both fossil and biomass processes since it is suitable for being directly used in low temperature FCs. Nevertheless, the round-trip efficiencies are only about $50 \%$; thus, some have argued that the establishment of an efficient 'electron economy' appears to be more appropriate than a 'hydrogen economy', except perhaps for niche applications [3].

Planning the hydrogen economy has been analyzed in different locations and reported in the literature, each plan considering particular aspects of this issue but with inadequate attention to the electric grid constraints; e.g. they are designed to meet the highest expected loads, that occur only in short intervals, while for the remaining times the power plants are underutilized and can deliver substantial energy to other sectors, with great advantages for the reliability of the system at the same time [4-10].

The existing power grids could then be used as the backbone of the hydrogen infrastructure system in combination with water electrolyzers, which can contribute to leveling the loads by changing operational current density in accordance with the changes of electricity demand. In fact, the hydrogen economy has been also defined as a future economy in which hydrogen is adopted for use in 'transports' and 'electric grid load balancing'; the need and potential for integrating energy conversion and storage in power systems with high renewable penetration is now recognized within electric utilities too, which set improvement of load factors as one of comprehensive measures for reduction of annual expenses and $\mathrm{CO}_{2}$ emissions [11-13].

Studies on renewable energy integration show that above certain penetration levels it affects grid stability and its capacity is typically limited to the minimum expected loads. One strategy for coping with intermittency of these resources is by diffusing its variability with transmission infrastructure; but with interconnections or spatial distances limited, it would be insufficient for leveling renewable energy. The other strategy is by storing energy that can be used to avoid the reliance on fossil-fueled generators to back-up renewable power; herein, the use of $\mathrm{H}_{2}$ for long-term energy storage has much better capacity than batteries and is also more versatile compared with pumped hydro or compressed air. Therefore, the needs for large-scale power storages on centralized grids relying extensively on renewables could tilt the choice of $\mathrm{H}_{2}$ as major energy carrier; moreover, there are many applications in which hydrogen is preferable to electricity, e.g. chemicals, heating or vehicles [14-18].

Summing up, hydrogen is likely to have a role to play for long-term storage in most grids that rely heavily on renewable inputs; the extent of this role requires full system modeling of each grid structure as well as other basic features, where the balancing tool provided by flexible $\mathrm{H}_{2}$ production needs to be specifically examined. This report is based on electricity powered $\mathrm{H}_{2}$ production which is a proven technology, thus providing a realistic analysis of the transition to hydrogen economy. In a previous work [7] we dealt with this issue using scenarios based in daily average power curves and simplified PEM electrolyzer models for hydrogen production, while in this study we use a holistic approach to generating system and consumption profiles on annual basis, together with a more comprehensive evaluation of the electrolysis processes that are applicable for grid loads at large scales; in a prospective view, the implementation of base-power and renewables, together with such processes, may provide a tool to managing the electrical system; using the excess electricity to produce hydrogen offers the possibility of increased capacities and load leveling, the hydrogen being subsequently stored and used for producing heat, power, synthetic fuels or simply pumping the gas into the existing natural gas infrastructure (i.e. power-to-gas).

\section{Electrolyzer modeling}

To evaluate water electrolysis, a concise model is selected to describe the $\mathrm{I}-\mathrm{V}$ characteristics of an electrolytic cell by means of thermodynamic, kinetic and electric resistance effects; the model assumes that the power consumed in the water electrolysis process is proportional to the square of the potential difference between the cell and water dissociation potentials, also considering the resistance of the cell, in such a form that the relationship between the voltage and current density can be expressed as:

$\left.V=U+2 K\left(J \cdot r+E_{0}\right)+\left(J^{2}+4 K \cdot E_{0} J\right)^{1 / 2}\right] / 2 K$

where the value of $E_{0}$ decides the starting point of the electrolysis curve which represents the water dissociation potential, the value of the resistance $r$ is relevant to the slope of the curve, and the value of the kinetic parameter $K$ influences both the slope and the curve shape [19].

On the other hand, the Faraday efficiency represents the ratio of hydrogen production and its theoretical value $(\Im=96,500 \mathrm{C} / \mathrm{eq})$, due to the parasitic losses which are important at elevated temperatures and low current densities [20]; this phenomenon can be described by Eq. (2).

$\eta_{F}=f_{1} \cdot J^{2} /\left(f_{2}+J^{2}\right)$

Therefore, we should notice that electrolyzers must be operated above a minimal intensity, in such a form that the current efficiency is practically not affected; this is especially important for alkaline water electrolyzers that are designed to manage fluctuating input currents and may only operate down to a minimum of about $10 \%$ of their rated power (idling current).

The energy yield of electrolyzers $\mathrm{E}\left(\mathrm{kWh} / \mathrm{kg}_{\mathrm{H} 2}\right)$ can thus be obtained directly from the voltage characteristics, the current and balance-of-plant (BOP) efficiencies (Eq. (3)); Fig. 1 shows the curve for a typical advanced water electrolyzer (AWE), where a nearly lineal relationship can be observed at elevated current densities.

$$
E=(\Im / 3600) \cdot V /\left(\eta_{F} \cdot \eta_{B O P}\right)
$$

We will focus on conventional water electrolyzers as they are the only technology currently available for large scale 

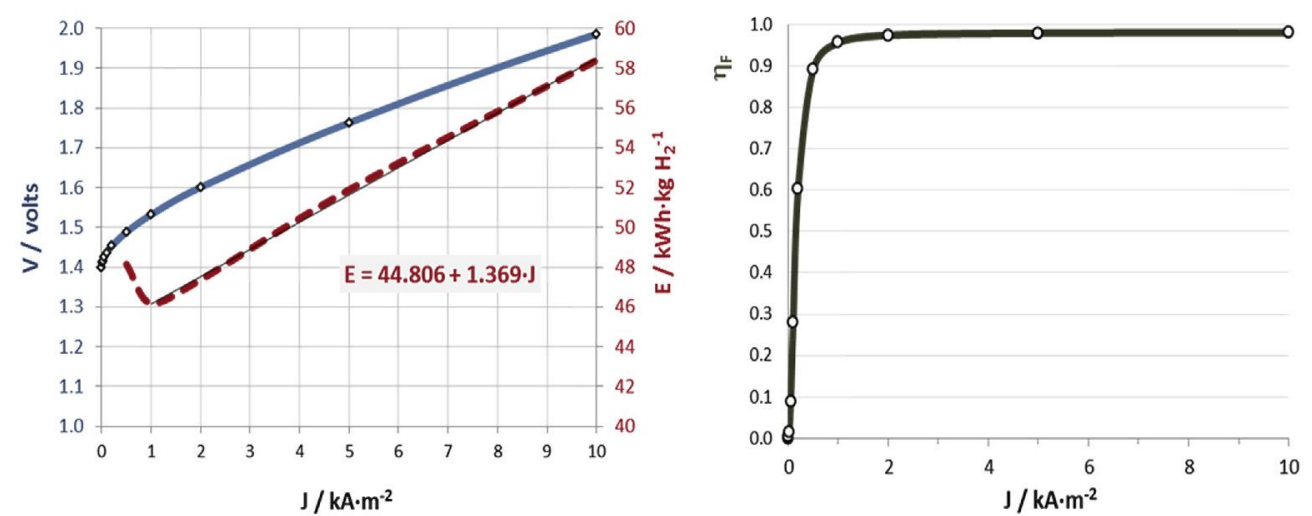

Fig. 1 - Efficiency curves for an advanced alkaline electrolyzer (AWE) with $E_{0}=1.40 \mathrm{~V}, \mathrm{~K}=120 \mathrm{~m}^{-1} \mathrm{~m}^{-2}$ and $r=0.020 \mathrm{~m} \Omega \mathrm{m}^{2}, f_{1}=0.98$ and $f_{2}=0.025 \mathrm{kA}^{2} \mathrm{~m}^{-4}\left(\right.$ at $80^{\circ} \mathrm{C}$ ), and $\eta_{\text {BOP }}=0.93$.

operations, through R\&D is still needed to tackle the energy problem and make flexible operation all the more relevant, as pointed out by Olabi [21] and Lund [22].

The US NREL regularly reviews the economics of hydrogen production by water electrolysis [13]. The direct capital cost of the plant is one of the three significant parameters in calculating the total costs from electrolysis - the other being the electrolyzer efficiency and cost of electricity. Process plants have generally a non-linear relationship between the cost of the plant and its production capacity $\left(C=W^{n}\right)$; sources in industry have confirmed this power law relationship with $\mathrm{n}=0.6-0.7$ for capacities up to about 1 ton $_{\mathrm{H} 2} /$ day, while costs rise nearly linearly beyond this point due to parallel construction of the stacks (i.e. maximum unit sizes is a target in itself for large installations) [23-27]. Looking ahead at markets for current technologies requires methods for estimating cost reductions as number of units increases by orders of magnitude; the consensus seems to be that developed markets will see costs coming down by a factor of two or more: a fair number to be used for purchased capital costs is between 200 and $400 € / \mathrm{kW}$, especially for large electrolyzers which operate at increased current densities [13,26] (Fig. 2):

$$
C_{E L}(€)=a \times Q_{0}\left(\mathrm{~kg}_{\mathrm{H} 2} / \mathrm{h}\right)^{b} \times J_{0}\left(\mathrm{kA} / \mathrm{m}^{2}\right)^{-c}
$$

Electrolyzer improvements typically target reduced capital costs by increasing intensity, using new materials, reducing complexity or by a combination of such methods; the current densities can be increased from typical values of $2 \mathrm{kA} / \mathrm{m}^{2}$ to approx. $10 \mathrm{kA} / \mathrm{m}^{2}$ by new membranes and reducing the gaps between electrodes. Balance-of-plant (BOP) costs - dominated by items like transformers, rectifiers and controllers comprise a significant part of the total installed costs; they also include water and hydrogen purifier if needed (the proportion is between 34 and $86 \%$ ).

Efficiency improvements are more limited, as there are thermodynamic principles which cap the top efficiency of a system; once this near-ideal efficiency is reached, cost reductions only could come from other areas, although this must be balanced with efficiency improvement for reducing the energy use. Based on information provided by suppliers, electrolyzers are now capable of producing hydrogen using less than $50 \mathrm{kWh} / \mathrm{kg}$, representing an efficiency greater than $67 \%$ based in the heating value (LHV: $33.5 \mathrm{kWh} / \mathrm{kg}$ ); this refers to the complete operation, including power electronics and other BOP components (that represent an additional 5-10\%).

Then, hydrogen production costs $\left(C_{H}, € / \mathrm{kg}\right)$ can be estimated using the expressions (below), which include the capital, operation and maintenance costs $\left(C_{C C}+C_{O \& M}, € / y r\right)$, and the inputs of electrolysis, i.e. electricity and water $\left(C_{E}+C_{W}\right.$,
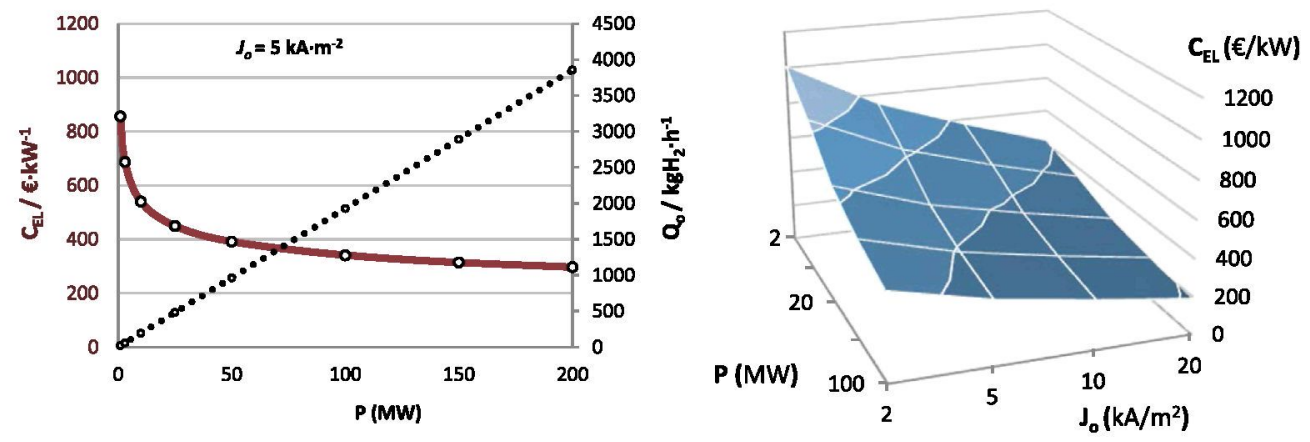

Fig. 2 - Costs for advanced alkaline electrolyzers with different power sizes and current densities $\left(a=1.20 \cdot 10^{5}, b=0.80\right.$, $\mathrm{c}=\mathbf{0 . 2 5 )}$. 
$€ /$ yr) (other costs as electrolytes, resins, etc. are not significant compared with the former).

$C_{H}=\left(C_{C C}+C_{O \& M}+C_{E}+C_{W}\right) / Q_{H}$

The capital costs are the purchased cost of electrolyzers (Eq. (4)) and BOP, by using a factor $F$ based on the annual discount rate and the number of years to recover the investment capital; the costs concerning the plant operation and maintenance, which also include the workforce, may be calculated as a rate of the investment capital (OM):

$\mathrm{C}_{\mathrm{CC}}+\mathrm{C}_{\mathrm{O \& M}}=(F+\mathrm{OM}) \cdot \mathrm{C}_{\mathrm{EL}+\mathrm{BOP}}$

The annual costs for electricity and water can be calculated from the power of the electrolytic plants $(P)$, their availability in hours per year $(u)$ and the prices of electricity and water $\left(C_{A i}\right)$ :

$C_{E}+C_{W}=8760 \cdot P \cdot u \cdot C_{A E}+9 \cdot Q_{H} \cdot C_{A W}$

Finally, the production of hydrogen $\left(\mathrm{Q}_{H}, \mathrm{~kg} / \mathrm{yr}\right)$ is the power input divided by the energy yield of the electrolyzer stack $(E$, $\mathrm{kWh} / \mathrm{kg}_{\mathrm{H} 2}$ ) which depends of the current-voltage characteristics, the Faraday and BOP efficiencies (Eqs. (1)-(3)):

$\mathrm{Q}_{H}=8760 \cdot P \cdot \mathrm{u} / \mathrm{E}$

We elaborated a worksheet to model the electrolyzer performance and hydrogen production costs, as shown above. The main inputs are the installed power, utilization ratio and nominal current density, the parameters for calculating the efficiency, and those related with the capital investment, annual depreciation, O\&M rates and the prices of energy and water.

Table 1 shows the output for an installation with a great capacity, running the electrolyzers at a moderately high current density and part utilization periods, and using low priced electricity; the results are a large electrolysis plant with high production, a diminished energy efficiency, and reduced costs of hydrogen due to the equipment and energy (the proportions are shown).
Sensitivity analyses indicate that power price is the most important factor, followed by energy use and then purchased capital cost; the importance of the electricity prices is the key reason why utilities need to be involved if the future hydrogen economy includes electrolysis. But this requires a holistic approach to current and future power systems, as depicted in next section.

\section{Power management using electrolytic hydrogen}

In this section we analyze the management strategies for surplus grid power using electrolytic hydrogen by means of annual curves that represent the power generation and demand along the year. When conventional base load and rolling power utilities are included in the analysis, this provides a completely new perspective for management of the whole electricity systems. For the study we have used the data provided by the Spanish operator (REE), relative to the energy demands and structure of power generation, with a disaggregation of hours $[28,29]$. The electrical system installed capacity was $102 \mathrm{GW}$ in 2013 and it was running at an overall capacity factor of only $29.7 \%$. Conventional utilities represent $61 \%$ of the total power capacity, with a coverage ratio of 1.57 over the peak hourly demand; moreover, the load duration curve shows that within the $1000 \mathrm{~h}$ of biggest annual consumption the power demand exceeds $5 \mathrm{GW}$. This is added to the geographical asymmetries of generation and demand along the country, which means costly grid reinforcements for transporting the electricity.

After introducing the special generation rules in 1997, the contribution of renewable energies to the power capacity in Spain has considerably risen, leading the country to a prime position in the world, though it is necessary to go further according with the energy targets for 2020 . At the same time, a great number of natural gas powered utilities were built in this period, till a point that the coverage with conventional generation only is near $60 \%$ as mentioned above. If we consider the utilization of each technology, the overcapacity running in the country leads to short utilization factors, except for nuclear, whereas penetration of renewables and falling of demand accentuate this situation. Table 2 shows all these factors, where if we take into account that some installations have grid priority (the 'special energies') we can foresee that they are conditioning the others, likely the thermal utilities

Table 1 - Worksheet for calculating the electrolyzer performance and hydrogen production costs.

Data inputs

Outputs

$\mathrm{C}_{\mathrm{H}}=4.00 € / \mathrm{kg}_{\mathrm{H} 2}$

Power capacity, P: $50 \mathrm{MW}$ u: $0.50 \quad \mathrm{~J}_{\mathrm{o}}: 5 \mathrm{kA} / \mathrm{m}^{2}$

Electrolyzer performance and costs: see Figs. 1 and 2

BOP cost: $60 \%$ of electrolyzer costs

Depreciation, d: $10 \%$ n: 20 years O\&M rate: $6 \%$

Electricity \& water, $C_{A E}: 0.05 € / \mathrm{kWh}, \mathrm{C}_{\mathrm{AW}}: 10 € / \mathrm{m}^{3}$
$\mathrm{V}_{\mathrm{O}}=1.76 \mathrm{~V} \eta_{\mathrm{F}}=0.98$

$E=51.9 \mathrm{kWh} / \mathrm{kg}_{\mathrm{H} 2}$

Ef. (LHV), $\eta=64.7 \%$

$\mathrm{C}_{\mathrm{EL}+\mathrm{BOP}}=31.3 \mathrm{M} €$

$\mathrm{Q}_{\mathrm{H}}=4220 \mathrm{t}_{\mathrm{H} 2} / \mathrm{yr}$ 
Table 2 - Power capacities and energy generation per technology (Spanish mainland system, 2013).

\begin{tabular}{lrcccc} 
Primary sources & Power capacity (MW) & Utilization factor & Generation (GWh) & Energy mix & Demand (GWh) \\
\hline Coal & 11,131 & $40.8 \%$ & 39,807 & 0 & $14.9 \%$ \\
Fuel + gas & 520 & $0.0 \%$ & 25,091 & $0.0 \%$ & - \\
Gas CC & 25,353 & $11.3 \%$ & 56,827 & $21.3 \%$ & - \\
Nuclear & 7,866 & $82.5 \%$ & 41,069 & $15.4 \%$ & - \\
Hydro + pumping & 19,887 & $23.6 \%$ & 54,338 & $20.4 \%$ & - \\
Wind & 22,854 & $27.1 \%$ & 49,410 & $18.5 \%$ & - \\
Other (special regime) & 14,786 & $38.1 \%$ & 266,542 & $100.0 \%$ & 246,313 \\
Total & 102,397 & $29.7 \%$ & & & - \\
\hline
\end{tabular}

(when used only as rolling power); moreover, the $\mathrm{CO}_{2}$ reductions would be less than anticipated due to cycling of the fossil fuel plants that make up the balance of the grid [30].

An interesting system aspect of electrolytic processes for the production of hydrogen is the possibility of grid management. Like all electrochemical energy converters they can respond to load changes almost immediately; in this way, highly dynamic electrolyzers could be used as variable electricity consumers, leading to higher utilization of power plants, with more stable prices, providing security and ancillary services, and avoiding costly line upgrades [31].

In this case, the choice of the equipment has influence on the power control capabilities of the system, trying to decrease transition times from their minimum loads to nominal operation and reduce the minimum loads to avoid electricity consumption when it is more expensive; if feed water and cooling are available, $20 \%$ overload shouldn't be a problem, but at lower efficiency; discontinuous operation may also induce additional degradation and maintenance costs [32].

As aforesaid, progress is expected as regards investment for mass produced electrolyzers; if demands for clean hydrogen increase, larger electrolyzer units could be built and the interest for flexible operation would be more manifest ( $\mathrm{a}$ reasonable size could be $50 \mathrm{MW}$ ).

The costs can be calculated from energy prices and electrolyzer depreciation: power markets fluctuate on hourly basis varying from 0 to $0.15 € / \mathrm{kWh}$ according to data in Spain (2010-12); since mean prices increase and depreciation decreases by the number of hours of operation, there will be an optimum of hours per year in which energy should be captured. On the other hand, we assume that hydrogen production has not impact on electricity prices; however, if it leads to high power needs to feed large electrolyzers, off-peak pricing would be impacted.

Hence, several production scenarios using base-load technologies and intermittent resources are superimposed to the power demands in each case, to create different electricity balances that can be converted to hydrogen by 'dynamic electrolyzer operations', as described above. For each scenario we can estimate the hydrogen producible in the 'valleys' as well as the $\mathrm{H}_{2}$ consumable during the 'peak' periods, by using the electrochemical conversion devices with electrolyzers and hydrogen; looking at the maximum surplus power values, we calculate the number and size of the electrolytic plants (e.g. for $P_{O i}=50 \mathrm{MW}, J_{0}=10 \mathrm{kA} / \mathrm{m}^{2}$ ); then, with the electrolyzer parameters (Fig. 1) we approximate the production of hydrogen by:

$\mathrm{Q}_{\mathrm{p}}\left(\mathrm{t}_{\mathrm{H} 2} / \mathrm{yr}\right)=\Sigma \mathrm{P}_{\mathrm{t}} / E_{t}=\Sigma u_{t} \mathrm{P}_{\mathrm{d}} /\left(k_{0}+k_{1} \cdot J_{t}\right)$

where we regulate the current density of the electrolyzers according to the utilization factor in each period: $J_{t}=u_{t} \cdot J_{0}$; $u_{t}=P_{t} / P_{0}\left(0.10 \leq u_{t} \leq 1.20\right)$.

The hydrogen consumable by fuel-cell generators is estimated from the power imbalances in the peak hours, using the typical electricity efficiency for these devices $(\eta=0.60)$ :

$\mathrm{Q}_{c}\left(\mathrm{t}_{\mathrm{H} 2} / \mathrm{yr}\right)=\mathrm{P}_{c}(\mathrm{MWh} / \mathrm{yr}) /\left[\eta \cdot \operatorname{LHV}\left(\mathrm{MWh} / \mathrm{t}_{\mathrm{H} 2}\right)\right]$

Finally, the hydrogen available for other uses, e.g. vehicle fuel, stationary energy or industrial processes, is obtained as:

$\mathrm{Q}_{a}=\mathrm{Q}_{p}-\mathrm{Q}_{c}$

Fig. 3a shows the hourly profiles, fixing a base-load power which is added to the production of non-manageable resources and compared with the real electricity demands during a year. In this scenario, we have simulated a base generation of $26,500 \mathrm{MWh}$ each hour of the year, which represents $92.4 \%$ of the annual power consumption, while the production from variable resources accounts for $30.7 \%$; the total surplus ratio is $123.1 \%$ and it means the net balance of electricity theoretically available for other uses $(58,042 \mathrm{GWh} /$ year). If this energy is used in relation with the hydrogen technologies for electric grid balancing, the model has to include: 1) the maximum power surplus (21.537 GW) which determines the capacity and utilization of electrolyzers (we use a limit value of $15 \mathrm{GW}$ ); 2) the hydrogen production, taking into account the inputs, the efficiency and dynamics of electrolyzers (1146.9 kt/y; u: 47\%); 3) the deficits of electricity originated by the power imbalances and electrolyzer's operation, that determine the peak regeneration (13.436 GW) and the hydrogen consumed in these devices (14.7\%). Fig. 3b displays the balances of electricity and hydrogen, showing electrolyzers operation, which is proportional to the loads within the dynamic range, and the FCs, that are activated from time to time to supply the power shortfalls $(7.0 \%)$.

We elaborated a worksheet in order to simulate distinct scenarios, taking into account all the model parameters: the 


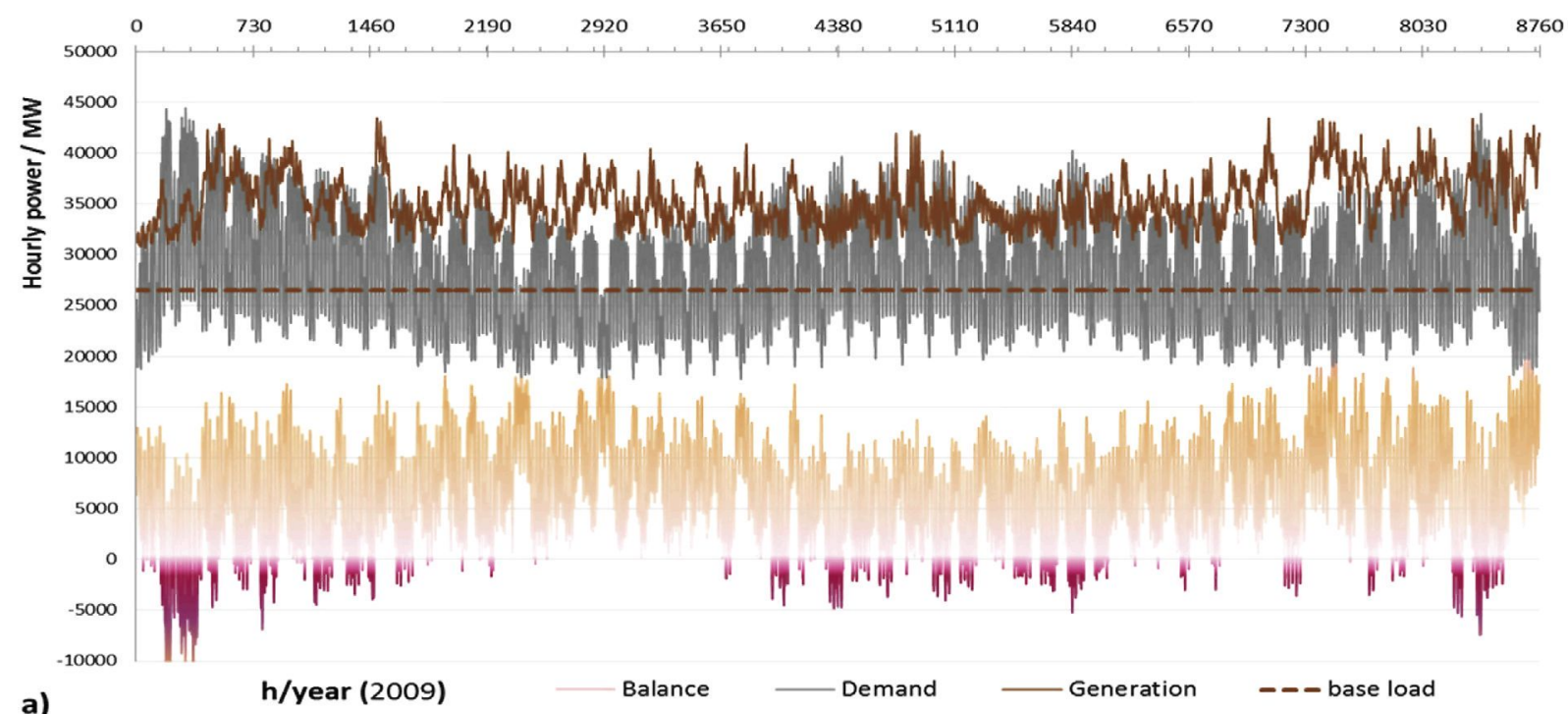

a)

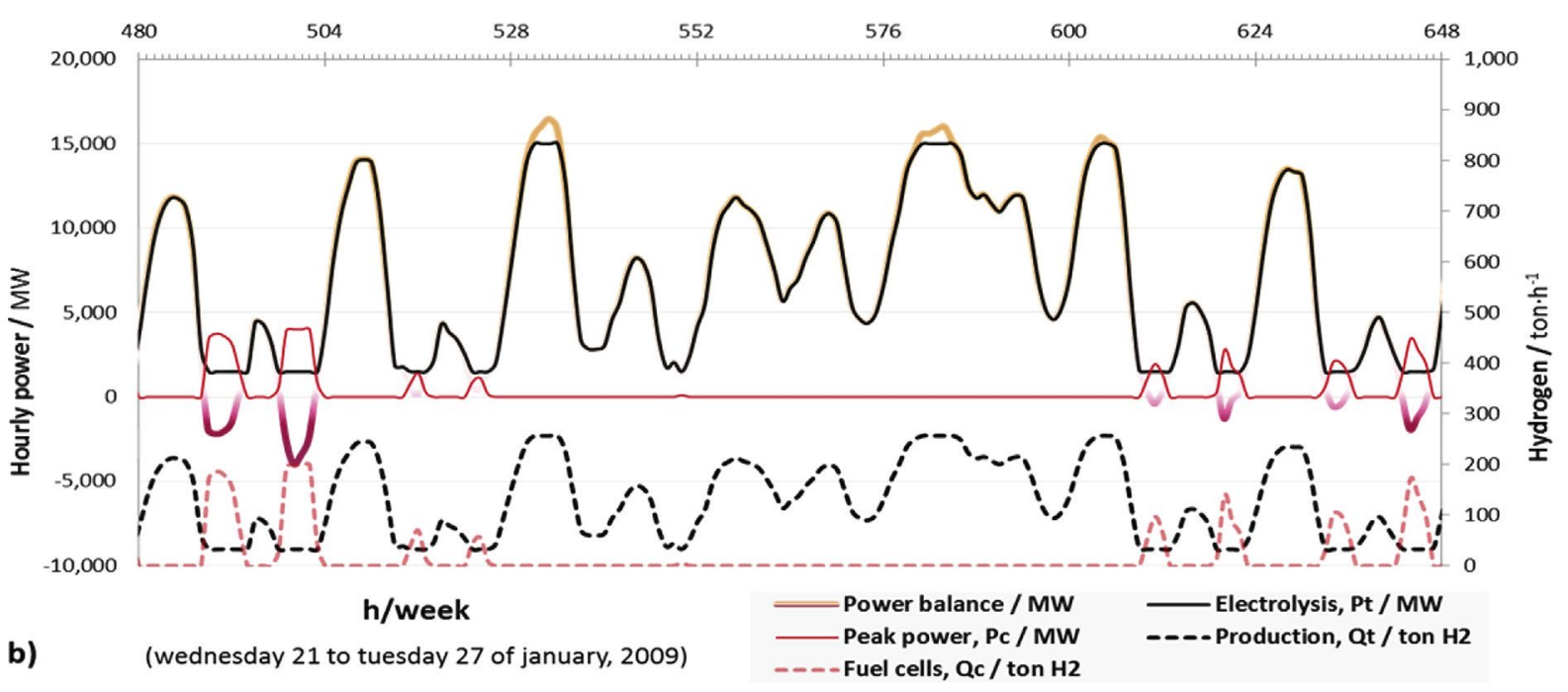

Fig. 3 - a) Power generation scenario and load curves with disaggregation of hours (Spain, 2009). b) Weekly balance of electricity and hydrogen using the electrolyzer and fuel-cell system.

most sensible factors are the base loads, the potential of electrolysis $E_{0}$, the faraday and BOP efficiencies, the limiting power to electrolyzers and FCs, the costs of these devices, the annual rates and, particularly, the electricity and hydrogen prices.

Such preliminary approaches deserve to be completed with analyses based in the projected demand time series for assessment of the required base-load and renewable power capacity, e.g. to meet regulatory milestones; to optimize the system we can use some criteria in order to maintaining the reliability of the grid and avoid extreme values, e.g. the utility is required to retain reserve capacity as a fraction of the expected peaks (minus the interruptible demand), while the size of electrolyzers is limited to capture $99 \%$ of the power surplus and the FCs are powered for a minimum of failures per year $(10 \mathrm{~h})$.
We can simulate all these conditions by fixing a typical reserve capacity amounting to $20 \%$ of conventional generation and the interruptible demands of $1916 \mathrm{MW}$ in the Spanish peninsula. Fig. 4a shows the effect of varying conventional power capacity on the size of electrolysis $(P)$, the FCs $\left(P_{c}\right)$ and net production of hydrogen $\left(Q_{a}\right)$, by maintaining the limits of power capture and failures per year as defined above; note that the zero value in this graphic corresponds to the conventional power capacity of the base-scenario (26,500 MW) and the range of values is between a minimum of $-4088 \mathrm{MW}$, where further power retirement makes management with hydrogen infeasible $\left(\mathrm{Q}_{\mathrm{a}}=0\right)$, and a maximum of $+8074 \mathrm{MW}$, where new power addition is not needful to meet the loads $\left(P_{c}=0\right)$. Fig. $4 b$ shows the economic balances for the different base generation scenarios and various surplus electricity prices, where positive values are reached by a proper 

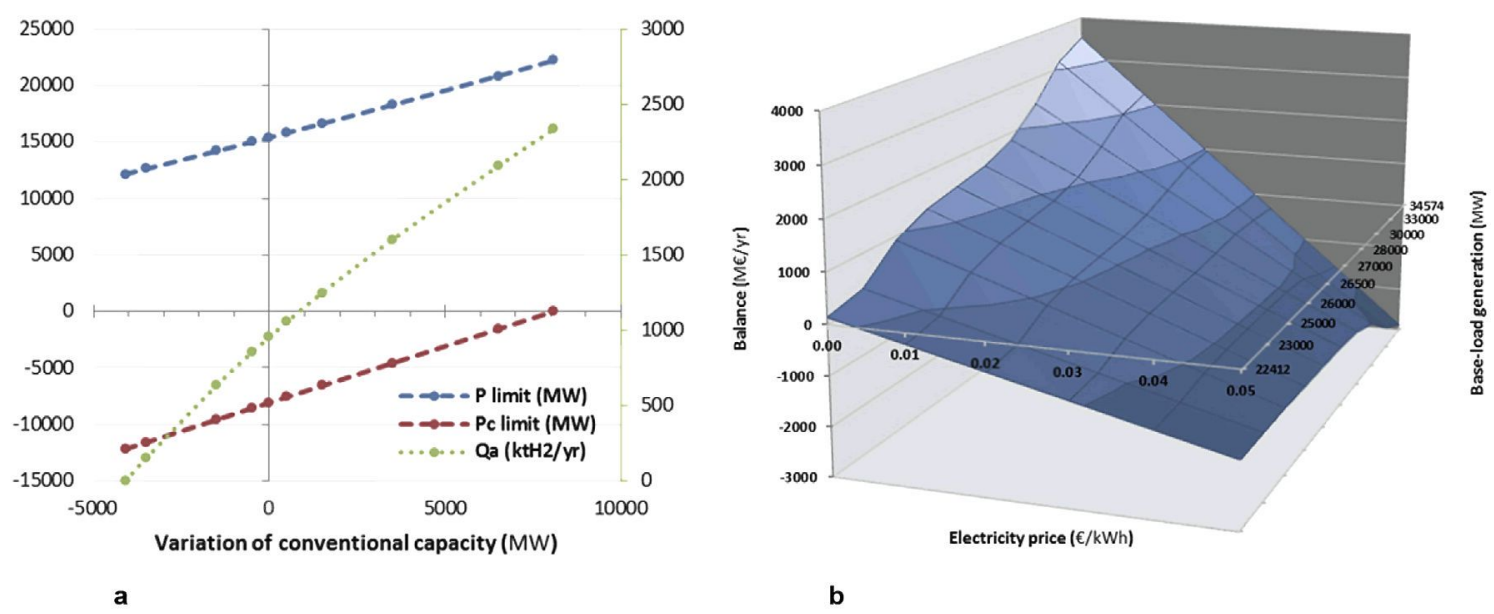

Fig. 4 - a) Effect of changes in base-power on the size and production of hydrogen systems. b) Effect of base-power and electricity prices on the global economic results.

combination of these parameters; i.e. increasing the base-load generation makes the grid and hydrogen operations the most profitable, even using higher prices to power the electrolyzers (for base-loading generation $\geq 26,500 \mathrm{MW}$ the break prices to render the system cost effective are between 0.02 and $0.03 € /$ $\mathrm{kWh}$ ); therefore, such scenarios are likely a good approach for management of the grids where conventional utilities, renewables and hydrogen storage can provide multiple advantages.

These results show the feasibility for power management using electrolytic hydrogen storage, while reducing conventional generation to less than a half of current capacities; this permits a high utilization factor of the technologies and maintain the contribution of renewable energies, at the same time that produces huge amounts of a clean fuel for the 'hydrogen economy'. When all these characteristics are retained together, low power prices (even near zero prices) for running the electrolyzers can be well justified on full economics of energy and policy basis.

In the base scenario, $300 \times 50 \mathrm{MW}$ future electrolyzer installations must be built in the country, each costing $24 \mathrm{M} €$. The mass of such installations assuming a power density of $870 \mathrm{~kW} / \mathrm{m}^{3}$, would be 171.6 ton per unit, thus amounting 51.5 kton for the whole country with a volume of approx. $17,240 \mathrm{~m}^{3}$ (excluding the balance of the system) and fitting in a space of $100 \times 40 \times 5 \mathrm{~m}^{3}$. The deployment flexibility of electrolyzers would allow for strategic placement: e.g. they may be placed within retired conventional facilities that have existing access to transmission grids; alternatively they may be placed nearby large wind mill developments or as highly distributed units located amongst end-users.

\section{Conclusions}

This report is the result of a pre-investigation of hydrogen technologies in the power systems, which considers two main aspects:
- State-of-the-art for electrolysis technology at large scales with respect to performance and costs, as well as future developments for the electrolyzer techniques.

- Potential for introduction in utility systems, by providing proper energy storage to power grids of given structures and penetration of variable sources.

The strategy is to control the power inputs, taking into account the dynamics of electrolyzers, to show the benefits of using surplus power at low price, as well as the leveling effects on the energy balances of the plants; the capacity of installations and power consumption determine the costs of the system, whereas they generate returns by selling hydrogen and electricity, and there are also savings in conventional fuels and utilities.

The analysis shows the effects of all factors relevant, including the variability of the loads, the parameters related to system operations, the costs of installations and the prices of energies. The economic balances are dominated by electricity costs and hydrogen sales in such a form that allowing for coproduction of hydrogen and power, utilities could improve their production, storage and use, and optimize the system based on economic or reliability factors.

Thus, the electric power industry is in a unique position, if the economy converts to hydrogen from clean energy sources, to increase the efficiency and reduce carbon and pollution levels. If electrolysis is used to produce the hydrogen, utilities could multiply the amounts of electricity they provide, and many could be provided without adding capacity; also, there are more than enough solar and wind resources to produce all the $\mathrm{H}_{2}$ needed as a clean, carbonfree fuel.

As concluding remark, with a large fraction of renewable sources in the energy system, water electrolysis is likely unavoidable even technology is not perfect. Efficiencies, short term costs and the advantages and drawbacks of the hydrogen technologies must then be discussed. However, a more fundamental question could be: what is the alternative, if business as usual is not an option? 